\title{
Tachykinin Receptor Antagonists Inhibit Hyperpnea-induced Bronchoconstriction in Guinea Pigs
}

\author{
Julian Solway, ${ }^{\star}$ Bob M. Kao, ${ }^{\star}$ John E. Jordan, * Bruce Gitter, ${ }^{*}$ lan W. Rodger, ${ }^{5}$ J. Jeffry Howbert, ${ }^{\star}$ \\ Linda E. Alger, * Jonathan Necheles, * Alan R. Leff, ${ }^{\star}$ and Allan Garland ${ }^{\star}$ \\ ${ }^{*}$ Section of Pulmonary and Critical Care Medicine, University of Chicago, Chicago, Illinois 60637; ${ }^{\ddagger}$ Lilly Research Laboratories, \\ Indianapolis, Indiana 46285; and ${ }^{\S}$ Merck-Frosst Center for Therapeutic Research, Pointe Claire-Dorval, Quebec H9R 4P8, Canada
}

\section{Abstract}

We tested the hypothesis that hyperpnea-induced bronchoconstriction (HIB) and hyperpnea-induced bronchovascular hyperpermeability (HIBVH) are mediated through stimulation of NK-1 and NK-2 receptors in guinea pigs. We first established the efficacy and selectivity of $( \pm)$ CP-96,345 (3 mg/ kg i.v.) and of SR-48,968 (300 $\mu \mathrm{g} / \mathrm{kg}$ i.v.) as NK-1 and NK-2 antagonists, respectively. $( \pm)$ CP-96,345 substantially attenuated bronchoconstriction and systemic vascular leak caused by administration of $\operatorname{Sar}^{9}, \operatorname{Met}\left(\mathrm{O}_{2}\right)^{11}$-Substance $P$ (a specific NK-1 agonist), but had no effect upon bronchoconstriction induced by selective NK-2 stimulation with $\mathrm{Nle}^{10}$-Neurokinin A[4-10]. Conversely, SR-48,968 antagonized the bronchoconstrictor response to $\mathrm{Nle}^{10}$-NK $\mathrm{A}[4-10]$, right-shifting the doseresponse curve by 2 log units, but had no effect on Sar', $\operatorname{Met}\left(\mathrm{O}_{2}\right)^{11}$-SP-induced bronchoconstriction. Anesthetized, tracheostomized, opened-chest male Hartley guinea pigs were pretreated with ( \pm ) CP-96,345 (3 mg/ kg i.v.), SR-48,968 (300 $\mu \mathrm{g} / \mathrm{kg}$ i.v.), or their respective vehicles, and Evans blue dye (30 $\mathrm{mg} / \mathrm{kg}$ i.v.) to label circulating albumin. $10 \mathrm{~min}$ isocapnic dry gas hyperpnea $(12 \mathrm{ml} / \mathrm{kg}, 150$ breaths/min) provoked HIB and HIBVH in vehicle-treated animals. $( \pm) C P-96,345$ reduced the magnitude of HIB by one-half (peak posthyperpnea RL 7.8 \pm 1.9 [SE] times prehyperpnea baseline versus $16.1 \pm 2.6$, vehicle-treated; $P \leq$ 0.0001, ANOVA); SR-48,968 blocked HIB more completely (peak posthyperpnea RL 5.1 \pm 1.7 [SE] times prehyperpnea baseline versus $19.3 \pm 2.8$, vehicle-treated; $P<0.0001$, ANOVA). Neither drug reduced HIBVH. We conclude that dry gas hyperpnea causes bronchoconstriction in guinea pigs through activation of tachykinin receptors. The differential effects of neurokinin receptor blockade on HIB and HIBVH demonstrate that hyperpnea-induced airflow obstruction is not primarily a consequence of hyperpnea-induced bronchovascular leak. (J. Clin. Invest. 1993. 92:315-323.) Key words: exercise-induced asthma $\bullet$ tachykinin $\bullet$ respiratory heat and water loss $\bullet$ bronchovascular hypermeability • C-fiber

Address correspondence to Dr. Julian Solway, Associate Professor of Medicine and Pediatrics, University of Chicago, 5841 South Maryland Avenue, MC 6026, Chicago, IL 60637.

Received for publication 15 July 1992 and in revised form 19 January 1993.

J. Clin. Invest.

(c) The American Society for Clinical Investigation, Inc. 0021-9738/93/07/0315/09 \$2.00

Volume 92, July 1993, 315-323

\section{Introduction}

Guinea pigs exhibit dry gas hyperpnea-induced bronchoconstriction $(\mathrm{HIB})^{1}(1,2)$ that phenomenologically resembles HIB in human subjects with exercise-induced asthma (3). Indirect evidence suggests that in guinea pigs dry gas HIB may be mediated by neuropeptides released from airway sensory $\mathrm{C}$ fiber nerves: In guinea pigs, HIB is ablated after chronic capsaicin pretreatment, which depletes sensory C-fibers of their neuropeptides, and is potentiated by administration of phosphoramidon, which inhibits neutral endopeptidase, the enzyme principally responsible for cleavage and inactivation of sensory neuropeptides in the airways (4). Guinea pigs also develop bronchovascular hyperpermeability after dry gas hyperpnea (5), though the potential role of sensory neuropeptides in this response is less certain. Given the prominent similarities between HIB in guinea pigs and HIB in human asthma, precise delineation of the mechanism of guinea pig airway responses to dry gas hyperpnea is of interest, for it may provide insight into mechanisms that could also operate in human asthma.

Sensory C-fibers contain a variety of neuropeptides, including the tachykinins substance $P$ (SP) and neurokinin A (NKA), that are released by a variety of physical and chemical stimulants. In the airways, these neuropeptides can modulate bronchomotor tone, bronchovascular tone, and bronchovascular permeability (3), by binding to cell-surface receptors that effect these responses. There are three types of neurokinin receptors, termed NK-1, NK-2, and NK-3. Each can bind several naturally occurring tachykinins, though the affinities of each receptor for the different tachykinin species differ appreciably. The NK-1 receptor exhibits greatest affinity for SP, and occurs both on guinea pig airway smooth muscle and on bronchial blood vessels. The NK-2 receptor is found on airway smooth muscle and exhibits greatest affinity for NKA. NK-3 receptors in the lung appear to be localized to intramural neural ganglia $(3,6)$. Recently, potent and specific nonpeptide antagonists for the NK-1 and NK-2 receptors have been described $(7,8)$. The NK-1 antagonist, CP-96,345, competitively antagonizes substance P-induced relaxation of norepinephrine-contracted dog carotid artery in vitro and inhibits SP-induced rat salivation in vivo (7-9); each of these responses to SP is thought to be mediated by NK-1 receptors. In addition, CP-96,345 inhibits airway plasma extravasation induced by intravenous SP,

1. Abbreviations used in this paper: DRC, dose-response curve; HIB, hyperpnea-induced bronchoconstriction; HIBVH, hyperpnea-induced bronchovascular hyperpermeability; NKA, neurokinin A; RL, pulmonary resistance; Rrs, respiratory system resistance; SP, tachykinin substance $\mathrm{P} ; \mathrm{V}_{\mathrm{T}}$, tidal volume. 
intravenous capsaicin, electrical vagal stimulation, or exposure to cigarette smoke $(10,11)$. The NK-2 antagonist, SR-48,968, blunts contraction of human bronchial rings induced by administration of a selective NK-2 receptor agonist in vitro, and can blunt NK-2 agonist-induced bronchoconstriction in vivo as well (8).

In this study, we established the selectivity and efficacy of ( \pm ) CP-96,345 as an NK-1 receptor antagonist and of SR48,968 as an NK-2 receptor antagonist, and then employed these agents to evaluate the role of NK-1 and NK-2 receptors in guinea pig airway responses to dry gas hyperpnea. Our results suggest that both NK-1 and NK-2 receptors mediate guinea pig HIB.

\section{Methods}

\section{Animal preparation and physiological measurements}

82 male Hartley guinea pigs ( $378-544 \mathrm{~g}$ ) were anesthetized with pentobarbital sodium $(75 \mathrm{mg} / \mathrm{kg}$ i.p.). A high cervical tracheostomy was intubated with a 13 gauge metal cannula, and each animal was mechanically ventilated (tidal volume $\left[\mathrm{V}_{\mathrm{T}}\right] 6 \mathrm{ml} / \mathrm{kg}$, frequency 60 breaths/min, termed "quiet breathing") using $50 \%$ oxygen in air, fully humidified at room temperature, as inspired gas. As described previously, the tracheal cannula was connected through a short common segment to inspiratory and expiratory ventilator tubing to minimize conditioning of inspired gas within the common segment (1). One carotid artery and one jugular vein were cannulated with PE-50 tubing; arterial pressure was monitored through the arterial cannula. Each animal then was placed within a 10.1-liter whole-body constant mass plethysmograph. Respiratory volume excursions were reflected in plethysmograph pressure fluctuations measured relative to a 20-liter reference chamber; respiratory flow was obtained by electrical differentiation of respiratory volume. Transthoracic pressure was measured as the difference between pressure at the tracheal cannula and plethysmograph pressure. Respiratory system resistance (Rrs) was calculated from the differences in transthoracic pressure and in flow, at isovolume points at mid-tidal volume (1). All physiological signals were recorded on a multi-channel pen recorder. Each animal received propranolol ( 1 $\mathrm{mg} / \mathrm{kg}$ i.v.) to minimize the influence of blood pressure changes (and possible consequent catecholamine release) upon airway tone $(5,12)$. Previously, we have shown that neither baseline Rrs nor the airway responses to dry gas hyperpnea are affected by propranolol administration $(5,12)$. Each animal was inflated to three times tidal volume prior to any intervention, to fix volume history.

\section{Evaluation of the efficacies and selectivities of neurokinin} receptor antagonists in modulating airway responses

Bronchoconstriction. The ability of ( \pm ) CP-96,345 to attenuate NK-1 receptor-mediated bronchoconstriction was evaluated as follows. Inspired oxygen fraction was increased from 50 to $100 \%$ during bronchoconstrictor administration. Bronchoconstriction dose-response curves were generated in guinea pigs by intravenous administration of the selective NK-1 agonist, $\mathrm{Sar}^{9}, \operatorname{Met}\left(\mathrm{O}_{2}\right)^{11}-\mathrm{SP}\left(\right.$ dose range $3 \cdot 10^{-11}-10^{-8}$ $\mathrm{mol} / \mathrm{kg}$ ) in increasing half-log steps. Respiratory system resistance was measured during quiet breathing at the peak bronchoconstrictor response after each dose, and then the next dose was administered without delay. After Rrs increased by at least threefold, bronchoconstriction was allowed to resolve. Either ( \pm ) CP-96,345 ( $3 \mathrm{mg} / \mathrm{kg}$ i.v.) or its vehicle (polyethylene glycol-400 [PEG-400], $1 \mathrm{~N} \mathrm{HCl,} \mathrm{normal} \mathrm{saline;}$ volume ratio 100:24:876) was then administered, and 20 min later, a second bronchoconstriction dose-response curve was generated in each animal, using the same selective NK-1 agonist as during the first dose-response curve. The estimated agonist log dose that would have tripled Rrs compared with baseline (the $\log \mathrm{ED}_{300}$ ) was calculated for each curve by linear interpolation between bounding experimental points, and the difference between $\log \mathrm{ED}_{300}$ values for the first and second curves (the $\Delta \log \mathrm{ED}_{300}$ ) in each animal was determined. If no dose of NK-1 selective agonist tripled Rrs, then $\mathrm{ED}_{300}$ was estimated as the lower of $(a)$ the $\log \mathrm{ED}_{300}$ calculated by extrapolation from the highest two agonist doses, or $(b)$ one-half log larger than the largest agonist dose administered. We chose to use $\Delta \log E_{300}$ as an index of drug or vehicle effect because it reduces the influence of interanimal variability in baseline constrictor responsiveness, which was evident in pilot studies. For each dose-response curve, baseline Rrs was taken as the value measured immediately prior to constrictor administration. $\Delta$ $\log \mathrm{ED}_{300}$ values from $( \pm)$ CP-96,345-treated animals were compared with $\triangle \mathrm{ED}_{300}$ values from vehicle-treated animals, to ascertain the efficacy of $( \pm$ ) CP-96,345 in blunting NK-1 agonist-induced bronchoconstriction. We tested also the selectivity of $( \pm)$ CP-96,345 by generating consecutive bronchoconstriction dose-response curves during administration of the selective NK-2 agonist, $\mathrm{Nle}^{10}$-NKA[4-10] (dose range $3 \cdot 10^{-11}-3 \cdot 10^{-8} \mathrm{~mol} / \mathrm{kg}$ ), in additional guinea pigs. Analogous to the experiments described above, NK-2 agonist dose-response curves were separated by administration of $( \pm)$ CP-96,345 ( $3 \mathrm{mg} / \mathrm{kg}$ i.v.) or vehicle; $\Delta \log \mathrm{ED}_{300}$ values from NK-1 antagonist-treated animals were compared to corresponding values from vehicle-treated animals.

The efficacy and selectivity of SR-48,968 in blunting NK-2 receptor-mediated bronchoconstriction was tested in a similar fashion, by comparing $\Delta \log \mathrm{ED}_{300}$ values determined from consecutive bronchoconstrictor dose-response curves generated in individual guinea pigs by administration of $\mathrm{Sar}^{9}, \mathrm{Met}\left(\mathrm{O}_{2}\right)^{11}-\mathrm{SP}$ or of $\mathrm{Nle}^{10}$-NKA [4-10]; consecutive dose-response curves were separated by treatment with SR48,968 ( $300 \mu \mathrm{g} / \mathrm{kg}$ i.v.) or its vehicle (PEG-200, normal saline; volume ratio: 1:19) given $30 \mathrm{~min}$ prior to generation of the second dose-response curve. If no dose of NK-2 selective agonist tripled Rrs, then log $\mathrm{ED}_{300}$ was estimated as the lower of: $(a)$ the $\log \mathrm{ED}_{300}$ calculated by extrapolation from the highest two agonist doses, or $(b)$ one-half log larger than the largest agonist dose administered.

Systemic vascular hyperpermeability. The ability of $( \pm)$ CP-96,345 to inhibit NK-1 agonist-induced systemic vascular hyperpermeability was assessed by measuring extravasation of Evans blue dye within the extrapulmonary (intrathoracic) airways, the large intrapulmonary airways, and the esophagus induced by administration of $\mathrm{Sar}^{9}$, $\operatorname{Met}\left(\mathrm{O}_{2}\right)^{11}$-SP. After preparation as described above, additional animals were treated with $( \pm)$ CP-96,345 ( $3 \mathrm{mg} / \mathrm{kg}$ i.v.) or vehicle; after 20 min, circulating albumin was labeled by administration of Evans blue dye $(30 \mathrm{mg} / \mathrm{kg}$ i.v. $)$, then $\operatorname{Sar}^{9}, \operatorname{Met}\left(\mathrm{O}_{2}\right)^{11}-\mathrm{SP}$ was given $\left(10^{-9} \mathrm{~mol} / \mathrm{kg}\right.$ i.v.). $10 \mathrm{~min}$ later, animals were killed by exsanguination, their systemic and pulmonary circulations perfused to remove intravascular dye, and their airways and esophagus excised (5). Extravascular Evans blue dye was extracted by incubation with formamide and determined colorimetrically as in prior studies (5). Pilot studies disclosed that administration of $\mathrm{Nle}^{10}-\mathrm{NKA}$ [4-10] caused minimal, if any, systemic vascular leak despite substantial bronchoconstriction; therefore, the role of NK-2 receptors in bronchovascular hyperpermeability was not pursued further in this study.

\section{Effects of neurokinin receptor antagonists on hyperpnea- induced airway responses}

Both ( \pm ) CP-96,345 and SR-48,968 were effective and selective antagonists of physiologic responses induced by selective stimulation of their target neurokinin receptors (see below). We therefore tested the roles of NK-1 and NK-2 receptors in hyperpnea-induced airway responses in guinea pigs as follows:

Animals were prepared as described above. Pilot studies demonstrated that a hypotensive effect of $( \pm$ ) CP-96,345 (see below) exacerbated the mild hypotension typically induced during mechanical hyperventilation of guinea pigs, and resulted in severe hypotension and death during hyperpnea. To reduce the incidence of this untoward complication, hyperpnea was performed in guinea pigs whose chests were opened by wide abdominal and bilateral diaphragm incision. (Note that in opened-chest animals, pulmonary resistance $(\mathbf{R L})$ was 
measured, rather than respiratory system resistance [Rrs]). After opening the chest in this fashion, animals were treated with $( \pm) \mathrm{CP}$ 96,345 ( $3 \mathrm{mg} / \mathrm{kg}$ i.v.) or its vehicle; or with SR-48,968 ( $300 \mu \mathrm{g} / \mathrm{kg}$ i.v.) or its vehicle. $20 \mathrm{~min}$ after $( \pm)$ CP-96,345 or $30 \mathrm{~min}$ after SR-48,968 (or vehicle), each animal received Evans blue dye $(30 \mathrm{mg} / \mathrm{kg}$ i.v.), and isocapnic hyperpnea $\left(V_{T} 12 \mathrm{ml} / \mathrm{kg}\right.$, frequency 150 breaths $/ \mathrm{min}$ ) of dry $95 \%$ oxygen $-5 \%$ carbon dioxide was mechanically imposed for $10 \mathrm{~min}$, followed by return to quiet breathing of humidified $50 \%$ oxygen for another $10 \mathrm{~min}$. Hyperpnea-induced bronchoconstriction was quantified as the ratio of peak posthyperpnea $R L$ to the prehyperpnea baseline RL ("RL Ratio"), analogous to the Rrs Ratio previously described (5). After 10 min quiet breathing, the animal was killed and tissue Evans blue content was determined as described above. Additional control animals were prepared and treated identically, except that 20 min quiet breathing (with no hyperpnea) were performed prior to killing and determination of extravasated Evans blue tissue contents. Enriched inspired oxygen mixtures are used to prevent severe arterial hypoxemia during bronchoconstriction; previously, we demonstrated that the magnitude of HIB is unaffected by increasing inspired oxygen fraction (12).

\section{Pharmaceuticals}

Pentobarbital sodium was purchased from Abbott Laboratories (North Chicago, IL), and racemic propranolol was purchased from Ayerst Laboratories, Inc. (New York, NY). ( \pm ) CP-96,345 was synthesized and purified by Lilly Research Laboratories (Indianapolis, IN). SR48,968 was synthesized and purified at the Merck Research Laboratories (Rahway, NJ). Evans blue dye was purchased from Sigma Chemical Co. (St. Louis, MO).

\section{Statistics}

Differences among groups were tested with one-way analysis of variance for fully randomized or repeated measures design, as appropriate; unpaired or paired $t$ tests were applied when only two value sets were compared. When ANOVA disclosed differences among groups, differences were localized using Fisher's least significant difference test. The Mann-Whitney test was used to test the effect of $( \pm)$ CP-96,345 on bronchoconstriction induced by a single administration of selective NK-1 agonist. Statistical significance was claimed whenever $P<0.05$.

\section{Results}

Evaluation of the efficacies and selectivities of neurokinin receptor antagonists in modulating airway responses

Effects of neurokinin receptor antagonists on baseline cardiorespiratory parameters. In these studies, ( \pm ) CP-96,345 was given to a total of 26 animals; 25 animals received its vehicle. To ascertain the influence of drug or vehicle upon Rrs (including values for $R_{L}$ ), mean arterial pressure, and heart rate, we compared preadministration parameters with paired values 20 min after administration. After ( \pm ) CP-96,345-vehicle alone, heart rate fell slightly, but there was no significant alteration in Rrs or blood pressure (Table I). In marked contrast, $( \pm)$ CP96,345 caused much greater bradycardia now accompanied by substantial hypotension; Rrs remained unchanged (Table I). In additional animals, atropine $(1 \mathrm{mg} / \mathrm{kg}$ i.v. $)$ pretreatment failed to prevent these cardiovascular consequences of $( \pm) \mathrm{CP}$ 96,345 administration (data not shown).

In contrast, neither SR-48,968 ( $n=18$ animals total) nor its vehicle ( $n=18$ animals total) exhibited much effect upon cardiorespiratory parameters (measured before and $30 \mathrm{~min}$ after administration). Neither treatment affected Rrs or blood pressure substantially, though each agent reduced heart rate slightly (Table I).

Bronchoconstriction. Respiratory system resistance was similar immediately prior to construction of each of the two consecutive dose response curves (DRC) generated by administration of NK-1 or NK-2 selective agonist (Table II); note that ( \pm ) CP-96,345 or SR-48,968 or their vehicles were administered 20-30 min before construction of the second DRC. Blood pressure preceding the second DRC was reduced compared with blood pressure preceding the first DRC in ( \pm ) CP96,345-treated animals that received NK-1 selective agonist. Analysis of variance demonstrated that both residual hypotension induced by $\mathrm{Sar}^{9}, \operatorname{Met}\left(\mathrm{O}_{2}\right)^{11}$-SP administration during the first DRC and the hypotensive effect of $( \pm)$ CP-96,345 (Table

Table I. Effects of Neurokinin Receptor Antagonists on Baseline Cardiorespiratory Parameters

\begin{tabular}{|c|c|c|c|}
\hline Treatment & $\begin{array}{l}\text { Respiratory system } \\
\text { resistance }\end{array}$ & $\begin{array}{l}\text { Arterial blood } \\
\text { pressure }\end{array}$ & Heart rate \\
\hline & $\mathrm{cm} \mathrm{H}_{2} \mathrm{O} \cdot \mathrm{ml}^{-1} \cdot \mathrm{sec}$ & $m m \mathrm{Hg}$ & beats/min \\
\hline \multicolumn{4}{|c|}{$( \pm)$ CP-96,345 Vehicle $(n=25)$} \\
\hline Before & $0.15 \pm 0.01$ & $42.8 \pm 1.9$ & $173 \pm 3$ \\
\hline After & $0.15 \pm 0.01$ & $44.3 \pm 1.8$ & $167 \pm 4^{*}$ \\
\hline \multicolumn{4}{|c|}{ ( \pm CP-96,345 (3 mg/kg i.v.) $(n=26)$} \\
\hline Before & $0.15 \pm 0.01$ & $44.3 \pm 2.0$ & $172 \pm 4$ \\
\hline After & $0.16 \pm 0.01$ & $33.3 \pm 1.8^{* \S}$ & $101 \pm 4^{* \S}$ \\
\hline \multicolumn{4}{|c|}{ SR-48,968 Vehicle $(n=18)$} \\
\hline Before & $0.12 \pm 0.01$ & $39.0 \pm 1.6$ & $174 \pm 4$ \\
\hline After & $0.13 \pm 0.01^{\ddagger}$ & $40.2 \pm 1.2$ & $163 \pm 4^{*}$ \\
\hline \multicolumn{4}{|c|}{ SR-48,968 $(300 \mu \mathrm{g} / \mathrm{kg}$ i.v. $)(n=18)$} \\
\hline Before & $0.12 \pm 0.01$ & $37.8 \pm 1.6$ & $179 \pm 4$ \\
\hline After & $0.12 \pm 0.01$ & $37.8 \pm 1.9$ & $164 \pm 3^{*}$ \\
\hline
\end{tabular}

Entries are mean \pm SEM.

Effect of Agent, After vs. Before ${ }^{*} P \leq 0.0005,{ }^{\ddagger} P<0.05$.

Effect of Drug vs. Effect of Vehicle ${ }^{\S} P<0.0001$ 
Table II. Baseline Respiratory System Resistance Before First and Second Dose-Response Curves

\begin{tabular}{|c|c|c|}
\hline \multirow[b]{2}{*}{ Treatment } & \multicolumn{2}{|c|}{$\begin{array}{l}\text { Respiratory system resistance } \\
\mathrm{cm} \mathrm{H}_{2} \mathrm{O} \cdot \mathrm{ml}^{-1} \cdot \mathrm{s}\end{array}$} \\
\hline & $\mathrm{Sar}^{9}, \operatorname{Met}\left(\mathrm{O}_{2}\right)^{11}-\mathrm{SP}$ & $\mathrm{Nle}^{10}-\mathrm{NKA}[4-10]$ \\
\hline \multicolumn{3}{|c|}{$( \pm)$ CP-96,345 vehicle } \\
\hline First DRC & $0.139 \pm 0.005$ & $0.173 \pm 0.009$ \\
\hline Second DRC & $\begin{array}{c}0.160 \pm 0.004 \\
(n=5)\end{array}$ & $\begin{array}{c}0.154 \pm 0.004 \\
(n=3)\end{array}$ \\
\hline \multicolumn{3}{|c|}{ ( \pm$) C P-96,345(3 \mathrm{mg} / \mathrm{kg}$ i.v. $)$} \\
\hline First DRC & $0.149 \pm 0.025$ & $0.169 \pm 0.011$ \\
\hline Second DRC & $\begin{array}{c}0.151 \pm 0.007 \\
(n=6)\end{array}$ & $\begin{array}{c}0.160 \pm 0.015 \\
(n=3)\end{array}$ \\
\hline \multicolumn{3}{|l|}{ SR-48,968 Vehicle } \\
\hline First DRC & $0.158 \pm 0.042$ & $0.141 \pm 0.007$ \\
\hline Second DRC & $\begin{array}{c}0.149 \pm 0.003 \\
(n=3)\end{array}$ & $\begin{array}{c}0.154 \pm 0.014 \\
(n=4)\end{array}$ \\
\hline \multicolumn{3}{|c|}{ SR-48,968 (300 $\mu \mathrm{g} / \mathrm{kg}$ i.v. $)$} \\
\hline First DRC & $0.124 \pm 0.004$ & $0.141 \pm 0.007$ \\
\hline Second DRC & $\begin{array}{c}0.125 \pm 0.011 \\
(n=4)\end{array}$ & $\begin{array}{c}0.154 \pm 0.007 \\
(n=4)\end{array}$ \\
\hline
\end{tabular}

Entries are mean \pm SEM.

I) contributed to this difference (blood pressures: $43.8 \pm 1.7$ [SEM] $\mathrm{mmHg}$, before first DRC; $33.7 \pm 4.2 \mathrm{mmHg}$, after first DRC and before $( \pm)$ CP-96,345; $24.3 \pm 3.6 \mathrm{mmHg}$, after $( \pm)$ CP-96,345 and before second DRC; $P=0.0004$, ANOVA; each condition different from the others, $P<.05$, least significant difference test). Blood pressure was also reduced prior to the second DRC constructed in SR-48,968-treated guinea pigs that received $\mathrm{Sar}^{9}, \operatorname{Met}\left(\mathrm{O}_{2}\right)^{11}$-SP. However, ANOVA demonstrated that this effect was attributable solely to a hypotensive effect of the NK-1 agonist (blood pressures: $43.3 \pm 3.4$ [SEM] $\mathrm{mmHg}$, before first DRC; $31.0 \pm 2.6 \mathrm{mmHg}$, after first DRC and before SR-48,968; $29.8 \pm 3.2 \mathrm{mmHg}$, after SR-48,968 and before second DRC; $P=0.009$, ANOVA; before first DRC different from after first DRC, $P<0.05$, least significant difference test; before SR-48,968 vs. after SR-48,968, $P=\mathrm{NS}$ ). Blood pressure was similar prior to construction of each of the consecutive dose-response curves in all other groups of animals.

Fig. $1 A$ presents typical pairs of dose-response curves generated in individual animals by infusion of the NK-1 selective agonist, $\operatorname{Sar}^{9}, \operatorname{Met}\left(\mathrm{O}_{2}\right)^{11}$-SP; consecutive curves were separated by administration of $( \pm$ ) CP-96,345 (right) or its vehicle (left). Administration of ( \pm ) CP-96,345 typically shifted the second NK-1 agonist dose-response curve to the right compared with the first, whereas vehicle had little or no effect on the position of the second dose-response curve. The postdrug or postvehicle change in $\operatorname{Sar}^{9}, \operatorname{Met}\left(\mathrm{O}_{2}\right)^{11}$-SP dose-response curve position was quantified by calculating the $\Delta \log \mathrm{ED}_{300}$ value for each animal. Individual and mean $\Delta \log \mathrm{ED}_{300}$ values from NK-1 antagonist or vehicle treated guinea pigs constricted with $\mathrm{Sar}^{9}, \operatorname{Met}\left(\mathrm{O}_{2}\right)^{11}$-SP are shown in Fig. $1 B($ left $)$. Compared with the effect of vehicle, $( \pm)$ CP-96,345 increased the threshold for NK-1 agonist-induced bronchoconstriction by $1.52 \operatorname{logs}(P<0.002)$. In marked contrast, $( \pm)$ CP-96,345 had no influence on the threshold for bronchoconstriction induced by the NK-2 selective agonist, $\mathrm{Nle}^{10}$-NKA[4-10] (Fig. 1 $B$, right $)$. Thus, at the dose administered, ( \pm ) CP-96,345 was an effective and selective physiological antagonist of NK-1 receptor-mediated bronchoconstriction.

Fig. $2 A$ shows the typical influence of SR-48,968 or its vehicle on NK-2 selective agonist-induced bronchoconstriction. The NK-2 receptor antagonist markedly blunts $\mathrm{Nle}^{10}$. NKA [4-10]-induced bronchoconstriction. In three of four animals, SR-48,968 administration resulted in almost total suppression of NK-1 agonist-induced bronchoconstriction in the

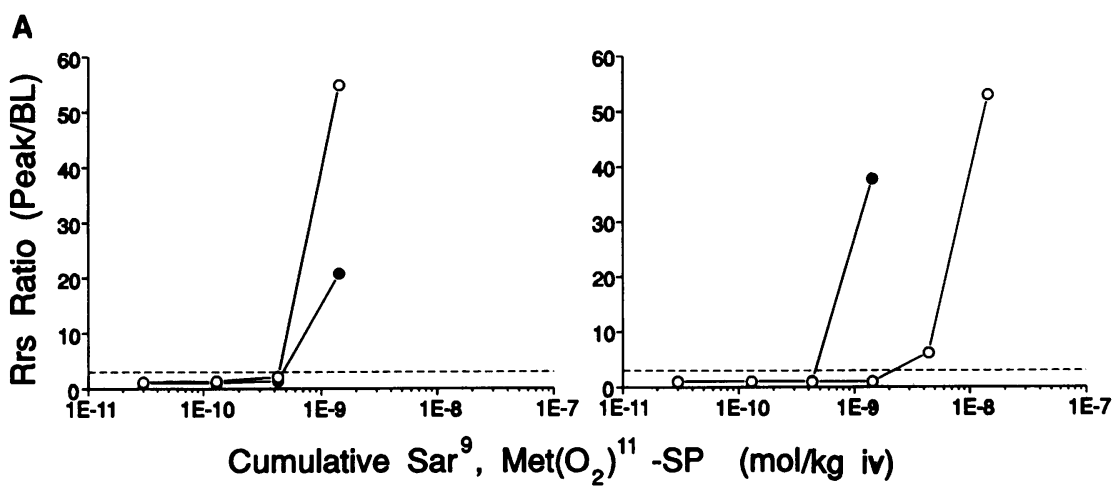

B

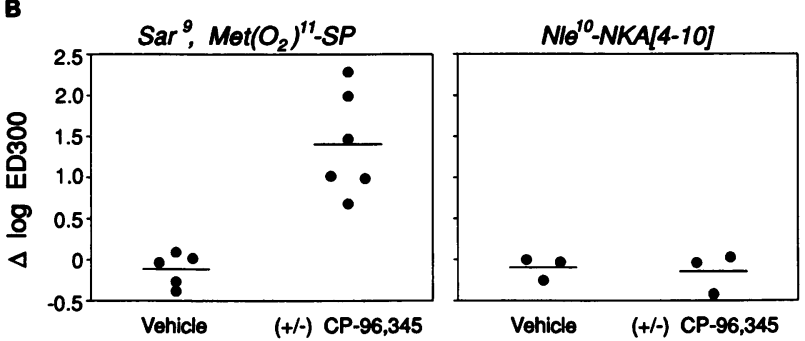

Figure 1. (A) Typical pairs of dose-response curves (DRC) generated in individual animals by infusion of the NK-1 selective agonist, Sar', $\operatorname{Met}\left(\mathrm{O}_{2}\right)^{11}$-SP; consecutive curves were separated by administration of $( \pm)$ CP-96,345 ( 3 $\mathrm{mg} / \mathrm{kg}$ i.v., right $)$ or its vehicle (left). Closed circles, first curve; open circles, second curve. Intersection of each DRC with broken line occurs at its $\mathrm{ED}_{300}$. $(B)$ Individual (closed circles) and mean (horizontal line) $\Delta \log \mathrm{ED}_{300}$ values from NK-1 antagonist- or vehicle-treated guinea pigs constricted with $\mathrm{Sar}^{9}, \operatorname{Met}\left(\mathrm{O}_{2}\right)^{11}$-SP (left) or $\mathrm{Nle}^{10}$-NKA [4-10] (right). 


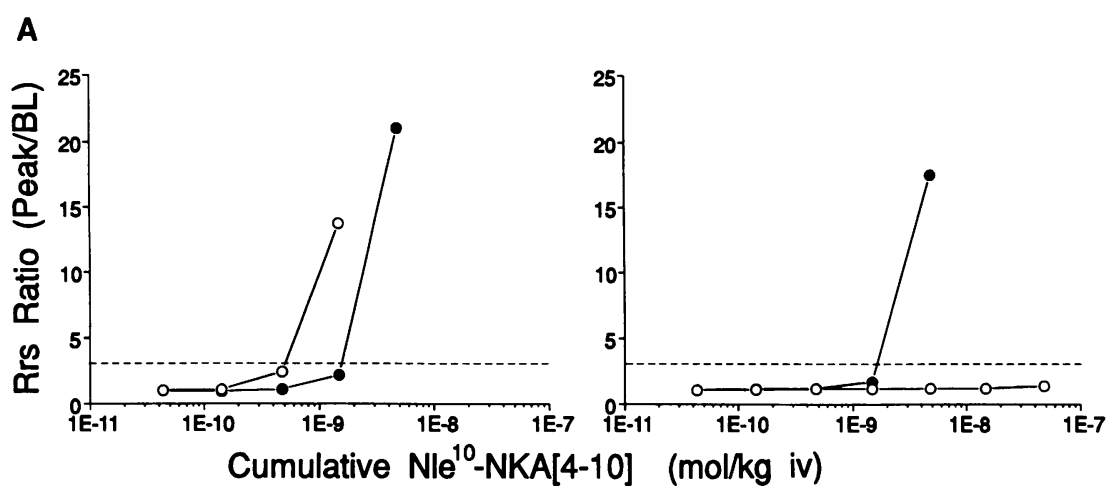

B

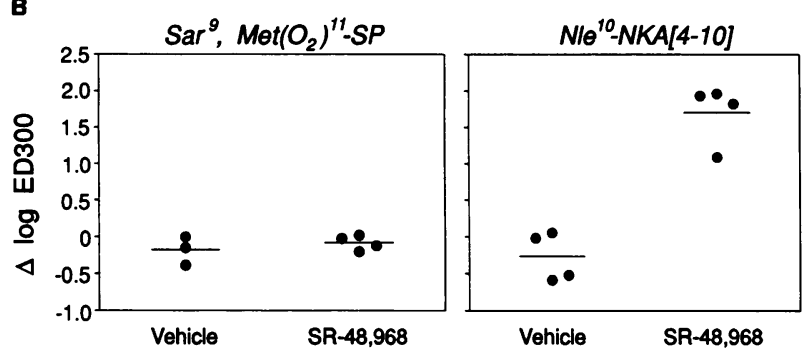

Figure 2. (A) Typical pairs of dose-response curves (DRC) generated in individual animals by infusion of the NK-2 selective agonist, $\mathrm{Nle}^{10}$ NKA [4-10]; consecutive curves were separated by administration of SR-48,968 ( $300 \mu \mathrm{g} / \mathrm{kg}$ i.v., right) or its vehicle (left). Closed circles, first curve; open circles, second curve. Intersection of each DRC with broken line occurs at its $\mathrm{ED}_{300}$. $(B)$ Individual (closed circles) and mean (horizontal line) $\Delta \log \mathrm{ED}_{300}$ values from NK-2 antagonist- or vehicle-treated guinea pigs constricted with $\mathrm{Sar}^{9}, \operatorname{Met}\left(\mathrm{O}_{2}\right)^{11}-\mathrm{SP}($ left $)$ or $\mathrm{Nle}^{10}$ NKA[4-10] (right). agonist dose range studied; in the fourth animal, a substantial right-shift of the second dose-response curve was apparent. In contrast, after vehicle administration, the second dose-response curve was usually slightly left-shifted compared with the first. Such potentiation of bronchoconstrictor responses with serial administration of tachykinins has been observed previously (13). Fig. $2 B$ presents individual and mean $\Delta \log \mathrm{ED}_{300}$ values from NK-2 antagonist or vehicle treated guinea pigs constricted with $\mathrm{Nle}^{10}$-NKA[4-10] (right). Compared with the effect of vehicle, SR-48,968 increased the threshold for NK2 agonist-induced bronchoconstriction by at least $1.97 \operatorname{logs}(P$ $<0.001)$. In marked contrast, SR-48,968 had no influence on NK-1 agonist-induced bronchoconstriction (Fig. $2 \mathrm{~B}$, left). Thus, in the dose employed, SR-48,968 was dramatically effective and selective in inhibiting NK-2 receptor-mediated bronchoconstriction.

Systemic vascular hyperpermeability. The ability of $( \pm)$ CP-96,345 to inhibit NK-1 agonist-induced systemic vascular hyperpermeability is demonstrated by results shown in Fig. 3. A single dose of $\operatorname{Sar}^{9}, \operatorname{Met}\left(\mathrm{O}_{2}\right)^{11}$-SP $\left(10^{-9} \mathrm{~mol} / \mathrm{kg}\right.$ i.v. $)$ was given to all animals. Animals pretreated with $( \pm)$ CP-96,345 ( $n$ $=4$ ) exhibited substantially reduced Evans blue extravasation in the extrapulmonary airways, the intrapulmonary airways, and the esophagus compared with vehicle pretreated animals $(n=4)$. ( \pm$)$ CP-96,345-treated animals also exhibited markedly blunted bronchoconstriction after NK-1 agonist administration (Rrs Ratio (peak/baseline): drug, 1.7 \pm 0.1 [SEM]; vehicle, $10.0 \pm 3.0 ; P<0.05$, Mann-Whitney); baseline Rrs values were similar in both groups.

\section{Effects of neurokinin receptor antagonists on hyperpnea- induced airway responses}

Prehyperpnea arterial blood pressure and $R_{L}$ values were similar among the four groups of animals studied to evaluate the influence of each neurokinin receptor antagonist (i.e., drug or vehicle, hyperpnea or quiet breathing). Dry gas hyperpnea elicited substantial posthyperpnea bronchoconstriction (Fig. 4). Both ( \pm ) CP-96,345 and SR-48,968 blunted hyperpnea-induced bronchoconstriction, though SR-48,968 was more effective in this regard (Fig. 4). Neither drug affected airway tone in control animals subjected to quiet breathing alone, though several animals that received vehicle for SR-48,968 (both with or without active drug) exhibited slowly increasing $R L$ in the last minutes of observation. Although we attempted combined administration of both NK-1 and NK-2 receptor antagonists, this combination resulted in severe hypotension in each of four animals, and therefore could not be studied during hyperpnea.

Dry gas hyperpnea also provoked bronchovascular hyperpermeability (HIBVH) in the extrapulmonary airways (Fig. 5 ), but there was no significant HIBVH in the intrapulmonary airways in these studies (Fig. 6). In contrast to the substantial

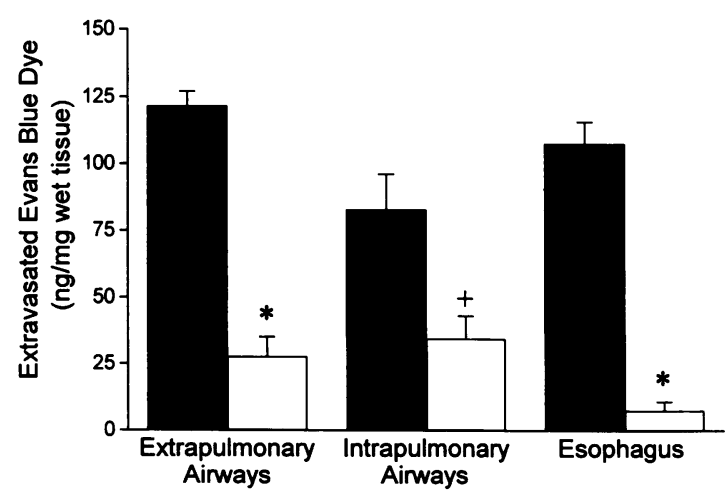

Figure 3. Inhibition of Evans blue dye extravasation induced by administration of $10^{-9}$ moles $/ \mathrm{kg}$ i.v. $\operatorname{Sar}^{9}$, $\operatorname{Met}\left(\mathrm{O}_{2}\right)^{11}$-SP. Solid bars, vehicle pretreated animals; open bars, $( \pm)$ CP-96,345-pretreated animals. Mean \pm SEM are shown. ${ }^{*} P<0.001 ;{ }^{+} P<0.03$. 


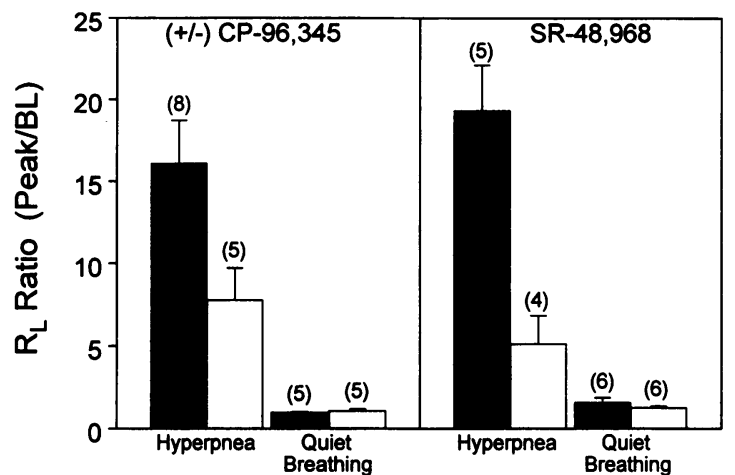

Figure 4. Inhibition of hyperpnea-induced bronchoconstriction by pretreatment with $( \pm)$ CP-96,345 (3 mg/kg i.v.) or with SR-48,968 $(300 \mu \mathrm{g} / \mathrm{kg}$ i.v.) as indicated. RL Ratio, ratio of peak posthyperpnea lung resistance to the prehyperpnea baseline $(B L)$ value. Solid bars, vehicle pretreated animals; open bars, drug pretreated animals.

Numbers in parentheses are the number of animals in each group in which determinations were made. Mean \pm SEM are shown.

inhibition of HIB seen with NK-1 or NK-2 receptor antagonist administration, neither drug significantly reduced hyperpneainduced bronchovascular hyperpermeability in the extrapulmonary airways (Fig. 5).

\section{Discussion}

This study establishes the participation of tachykinin receptors in hyperpnea-induced bronchoconstriction (HIB) in guinea pigs. Previously, the presumption that sensory neuropeptides contribute to guinea pig HIB was supported only by indirect evidence, and the role of neurokinin receptor subtypes in HIB was wholely unexplored. Ray et al. (4) showed that chronic capsaicin pretreatment blunts HIB in these guinea pigs and that inhibition of neutral endopeptidase with phosphoramidon potentiates the bronchoconstrictor response to dry gas hyperpnea. Capsaicin pretreatment depletes a subpopulation of sensory C-fibers of their neuropeptides, so that on subsequent stimulation, there is little, if any, neuropeptide released (14). Diminution of a variety of airway responses after chronic capsaicin

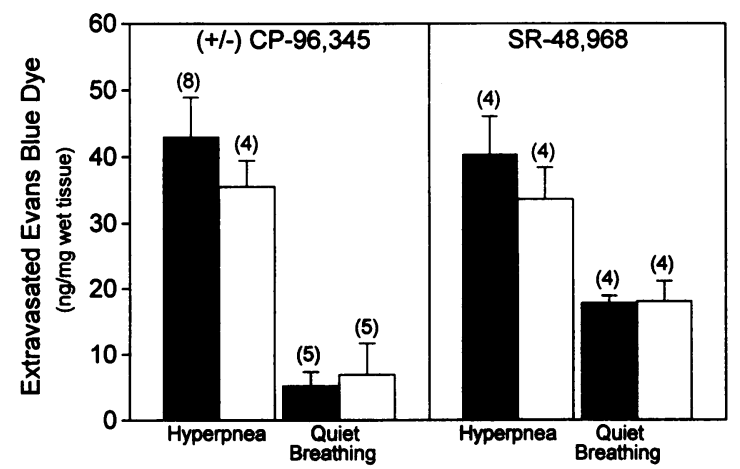

Figure 5. Effects of hyperpnea and of pretreatment with ( \pm ) CP96,345 ( $3 \mathrm{mg} / \mathrm{kg}$ i.v.) or SR-48,968 (300 $\mu \mathrm{g} / \mathrm{kg}$ i.v.) on bronchovascular permeability in the extrapulmonary, intrathoracic airways. Solid bars, vehicle pretreated animals; open bars, drug pretreated animals. Numbers in parentheses are the number of animals in each group in which determinations were made. Mean \pm SEM are shown.

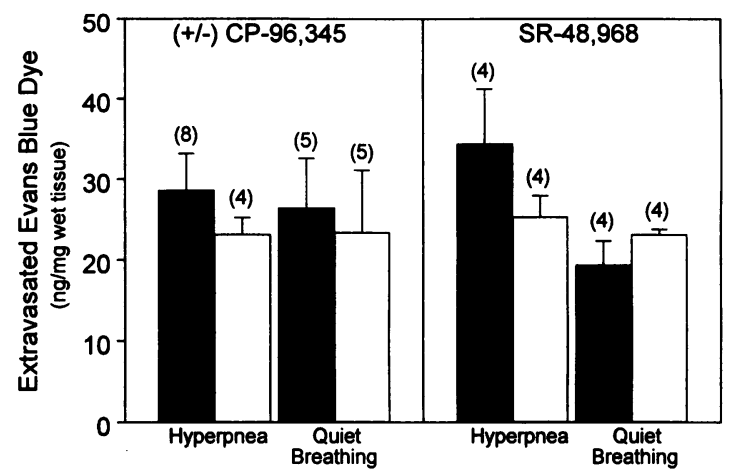

Figure 6. Effects of hyperpnea and of pretreatment with ( \pm ) CP96,345 ( $3 \mathrm{mg} / \mathrm{kg}$ i.v.) or SR-48,968 (300 $\mu \mathrm{g} / \mathrm{kg}$ i.v.) on bronchovascular permeability in the central intrapulmonary airways. Solid bars, vehicle pretreated animals; open bars, drug pretreated animals. Numbers in parentheses are the number of animals in each group in which determinations were made. Mean \pm SEM are shown.

pretreatment has been taken as indirect evidence for sensory neuropeptide involvement in those responses (15-17). Conversely, neutral endopeptidase (NEP) is the enzyme that is chiefly responsible for cleavage and inactivation of tachykinins released within the airway wall. Inhibition of this enzyme prolongs survival of active tachykinins, and thus potentiates their physiologic effects. Although neutral endopeptidase also metabolizes other inflammatory peptide mediators (such as formylmethionyl-leucyl-phenylalanine) (18), potentiation of an airway response by administration of NEP inhibitors has also been taken as presumptive evidence of likely tachykinin participation in that response (19).

The present study provides the first pharmacologic evidence that tachykinin receptors mediate guinea pig HIB; we demonstrate that specific antagonism of the each of the two subtypes of neurokinin receptors found on guinea pig bronchial smooth muscle (20) substantially inhibits HIB in these animals (Fig. 4). The strength of this conclusion rests on the effectiveness and selectivities of the two receptor antagonists employed, which therefore bear close examination. We used nonpeptide antagonists of the NK-1 ([ \pm ] CP-96,345) and NK2 (SR-48,968) receptors. To evaluate the efficacy of each agent, we generated two consecutive dose-bronchoconstrictor response curves in individual guinea pigs, by administering specific stimulants of the NK-1 or NK-2 receptor (Sar', $\operatorname{Met}\left(\mathrm{O}_{2}\right)^{11}$-SP or Nle ${ }^{10}$-NKA[4-10], respectively); the selectivity of each agonist has been previously established (21). In each animal, the second curve followed administration of active drug or its vehicle alone. By comparing the shift in sensitivity to constrictor agonist between curves separated by drug or by vehicle, the inhibitory influence of drug alone could be assessed. We chose this approach, rather than performing single dose-response curves in separate groups of drug- or vehiclepretreated animals, because pilot studies demonstrated that the dose-response curves to these constrictor agonists were steep (see Figs. $1 A$ and $2 A$ ), and the threshold dose for bronchoconstriction varied over about a one-half log range. By using each animal as its own control, the adverse influence of interanimal variability in sensitivity was reduced. We found that administration of either NK-1 or NK-2 selective agonist caused bron- 
choconstriction in a dose-dependent fashion. ( \pm ) CP-96,345 inhibited bronchoconstriction induced by NK-1 stimulation in vivo, but had no effect upon NK-2 agonist-induced constriction (Fig. $1 B$ ). Conversely, SR-48,968 was markedly effective in blunting NK-2 agonist-induced bronchoconstriction in vivo, but had no influence upon NK-1 receptor-mediated constriction (Fig. $2 \mathrm{~B}$ ). Thus, in the doses employed in this study, each agent apparently functioned as an effective and selective antagonist of its target receptor. Our demonstration that administration of $( \pm)$ CP-96,345 or of SR-48,968 each substantially blunt hyperpnea-induced bronchoconstriction therefore implicates the participation of both NK-1 and NK-2 receptors in this response in guinea pigs.

It is important to acknowledge the possibility that either ( \pm ) CP-96,345 or SR-48,968 might have influenced HIB through activities other than tachykinin receptor antagonism. To date, there have been no reports that SR-48,968 has important biological activities other than NK-2 receptor antagonism. However, Schmidt et al. recently showed that CP-96,345 interacts with L-type calcium channels (22), perhaps leading to calcium channel blockade that may explain the adverse cardiovascular effects seen here. In our study, $( \pm)$ CP-96,345 did not suppress airway smooth contractility nonspecifically, as evidenced by its lack of effect on $\mathrm{Nle}^{10}$-NKA[4-10]-induced bronchoconstriction (Fig. 2). It remains conceivable, though, that calcium channel blocking activity contributed to its influence on HIB through action at some other airway structure. For example, one might speculate that $( \pm)$ CP-96,345 inhibits tachykinin release from sensory C-fibers (23). Final proof of the participation of NK-1 or NK-2 receptors in guinea pig HIB will require demonstration that multiple, structurally diverse, specific antagonists of either receptor subtype inhibit this response.

Although tachykinin receptors play a major role in hyperpnea-induced bronchoconstriction in guinea pigs, they do not contribute importantly to HIBVH in the extrapulmonary intrathoracic airways, where this response is consistently most marked (reference 5, Figs. 5 and 6). As shown in Fig. 5, neither neurokinin receptor antagonist blunted HIBVH in the extrapulmonary airways. Since administration of the NK-1 receptor antagonist dramatically reduced the bronchovascular leak induced by NK-1 stimulation (Fig. 5), the lack of reduction of HIBVH by $( \pm)$ CP-96,345 strongly speaks against the potential role of NK-1 receptors in HIBVH in this airway region. It remains conceivable, though unlikely, that a larger dose of antagonist might have blunted HIBVH, but drug-induced hypotension (see below) prevented testing this possibility. The lack of effect of NK-2 receptor antagonism on HIBVH is consistent with our finding that NK-2 stimulation with $\mathrm{Nle}^{10}$-NKA[410] caused little if any Evans blue dye extravasation despite considerable bronchoconstriction. Thus, it appears that the NK-2 receptor is incapable of generating bronchovascular hyperpermeability to albumin. Nonetheless, we tested the effect of NK-2 blockade on HIBVH, to entertain the possibility that other potential effects of NK-2 stimulation (e.g., release of other mediators [3]) in part determine the magnitude of HIBVH. Our results suggest that they do not. The unchanged persistence of HIBVH in the extrapulmonary airways after NK-1 or NK-2 receptor blockade thus strongly speaks against the role of tachykinins in this phenomenon, as predicted by our earlier demonstration that capsaicin pretreatment has no signif- icant effect on HIBVH in the extrapulmonary airways (5). The mediators that are responsible remain to be fully identified, but preliminary evidence from other studies suggests that eicosanoids may participate in this response (24).

Our results also demonstrate that the airflow obstruction induced by dry gas hyperpnea is not primarily a consequence of acute hyperpnea-induced bronchovascular hyperpermeability. In this study, dry gas hyperpnea did not significantly increase Evans blue dye extravasation into the intrapulmonary central airways, over that observed in control animals subjected to quiet breathing. On the surface, this result appears to differ somewhat from our previous study (5), in which dry gas hyperpnea did increase bronchovascular leak slightly in this airway region. However, comparison of the results of these two studies suggests that in the present study, the extravasation of Evans blue dye was relatively elevated in quiet-breathing control animals. This apparent increase in "background" permeability could have prevented identification of the small effect on intrapulmonary bronchovascular permeability that hyperpnea appeared to have had previously (5). Two important methodologic differences between the studies could have contributed to this variance. First, dry gas hyperpnea was performed in opened-chest animals in the current study due to drug-induced hypotension (see below), whereas previously we studied closed-chest animals (5). Second, the present study involved administration of drugs and vehicles that were not included previously (5). It is conceivable that either the thoracic surgery or the solubilizing agents used in the vehicles for the NK-1 and NK-2 antagonists themselves increased bronchovascular permeability slightly. In any event, the present study demonstrates substantial dissociation of: $(a)$ the magnitudes of hyperpneainduced bronchoconstriction and bronchovascular hyperpermeability, and $(b)$ the influence of NK-1 and NK-2 receptor antagonism in those responses. Together, these findings indicate that the bronchovascular leak that may be caused by dry gas hyperpnea cannot be primarily responsible for the airflow obstruction induced by dry gas hyperpnea (i.e., HIB).

It is important to consider the potential limitations of this study. ( \pm ) CP-96,345 caused hypotension and bradycardia, presumably impairing cardiac output in treated animals. Though it indicates that $( \pm)$ CP-96,345 itself may be unsuitable as a drug for use in man, we think that this untoward drug effect could not have caused us to reach erroneous conclusions in the present study. First, diminished airway blood flow (as might have occurred in ( \pm ) CP-96,345-treated animals) has been shown to prolong bronchoconstriction induced by inhaled histamine (25), perhaps by impairing constrictor clearance. One might therefore expect that the hypotension induced by this drug would have potentiated, not inhibited, bronchoconstriction during the second of consecutive dose-response curves. Second, it might be argued that the hypotension induced by ( \pm ) CP-96,345 impaired $\operatorname{Sar}^{9}, \operatorname{Met}\left(\mathrm{O}_{2}\right)^{11}$-SP delivery to the airways during generation of the second dose-response curve, thereby reducing bronchoconstriction; the apparent effectiveness of the NK-1 blocker would then be artifactually related to impaired drug delivery, rather than true NK-1 receptor antagonism. However, this hypothesis cannot be accepted, for hypotension was induced by $( \pm)$ CP-96,345 during Nle ${ }^{10}$-NKA [410] administration, and presumably impaired the delivery of this NK-2 stimulant to the airways as well; yet the NK-1 receptor antagonist had no effect on NK-2 agonist-induced broncho- 
constriction. Third, perhaps related to their opened chests, pretrial blood pressure was similar in vehicle- and $( \pm)$ CP-96,345treated animals that received hyperpnea or quiet breathing alone. This finding minimizes the possibility that altered airway blood flow affected the magnitude of hyperpnea-induced bronchoconstriction in $( \pm)$ CP-96,345-treated guinea pigs. Fourth, because reduced airway blood flow has been shown to inhibit plasma extravasation (26), the potential reduction of airway blood flow by $( \pm)$ CP-96,345 would have tended to reduce HIBVH in drug treated animals; the absence of reduction of HIBVH by NK-1 antagonist administration is in the opposite direction to the potential artifact, and thus cannot be attributable to it. There was no substantial adverse cardiorespiratory effect of the NK-2 receptor antagonist employed here.

A second potential limitation of this study is that single doses of neurokinin receptor antagonists were employed, and that only one level of stimulus intensity was used in dry gas hyperpnea challenges. However, we do not feel that either of these features of our study design substantially limited the knowledge gained here. Cardiovascular toxicity limited the useful dosage of $( \pm)$ CP-96,345 to $3 \mathrm{mg} / \mathrm{kg}$ i.v., as employed here; in pilot studies, administration of higher doses resulted in excessive mortality. Still, this agent/dose combination reduced the bronchoconstrictor sensitivity to selective NK-1 stimulation by over 30 times, and it markedly blunted very substantial NK-1 agonist-induced systemic vascular leak. Thus, though it remains possible that a more effective NK-1 blocking regimen might have yielded greater physiological effects, the regimen employed here was sufficiently efficacious to implicate the participation of NK-1 receptors in HIB. The dose of SR-48,968 ( $300 \mu \mathrm{g} / \mathrm{kg}$ i.v.) employed in these studies is eight times the median inhibition dose ( (D $_{50}, 37 \mu \mathrm{g} / \mathrm{kg}$ i.v.) that Emonds-Alt et al. (8) found necessary to suppress $\mathrm{Nle}^{10}$-NKA [4-10]induced bronchoconstriction in guinea pigs in vivo. After administration of SR-48,968 (300 $\mu \mathrm{g} / \mathrm{kg}$ i.v.), the threshold dose of NK-2 agonist necessary to provoke substantial bronchoconstriction (here, tripling of respiratory system resistance) was increased by at least 93 -fold. Thus, it is unlikely that inadequate NK-2 receptor blockade occurred and failed to disclose important NK-2 effects. Although we attempted to deliver both agents simultaneously, the combination resulted in excessive hypotension and could not be studied during hyperpnea. Also, as noted above, $( \pm)$ CP-96,345 possesses calcium channel blocking properties (22). Though this agent exhibited no nonspecific suppression of tachykinin-induced bronchoconstriction in our study (see Fig. $1 B$ ), it remains conceivable that $( \pm$ ) CP-96,345 (or even SR-48,968) exerted its effect on hyperpnea-induced bronchoconstriction through an activity other than neurokinin receptor antagonism. Finally, in this study we employed a single, large stimulus intensity during dry gas hyperpnea (as determined by minute ventilation and duration of hyperpnea). We have previously demonstrated that the severity of hyperpnea-induced bronchoconstriction follows a linear stimulus-response relationship with both minute ventilation $(1,2,4)$ and duration of (12) dry gas hyperpnea. The hyperpnea conditions chosen for the present experiments impose a large constrictor stimulus, in the upper range of intensity compared with all other studies of hyperpnea-induced bronchoconstriction in guinea pigs of which we are aware. Given the clearcut effects of NK-1 or NK-2 receptor antagonist administra- tion at this large stimulus intensity, it is conceivable that these agents might blunt HIB even more completely at lower stimulus levels.

A third limitation of this study is that it does not identify which naturally occurring tachykinin species are important in stimulating NK-1 and NK-2 receptors after dry gas hyperpnea. Both substance $P$ and neurokinin $A$ can be released from sensory C-fibers, and each can bind to and activate both the NK-1 and NK-2 receptors (20). This nonselectivity of individual receptor subtypes for native tachykinin species (and vice versa) precludes assignment of a principal role for SP or NKA in HIB based upon our results.

This study is important because it establishes the participation of NK-2 receptors in guinea pig HIB, and suggests the participation of NK-1 receptors in this airway response as well. Hyperpnea-induced bronchoconstriction in guinea pigs closely phenomenologically resembles HIB in human subjects with exercise-induced asthma. In light of this behavioral similarity, it seems likely that common pathogenetic mechanisms may operate during HIB in both guinea pigs and asthmatic humans. The results of the present study therefore prompt the hypothesis that tachykinin release participates in the mechanism of HIB in human exercise-induced asthma. This hypothesis remains to be tested.

\section{Acknowledgments}

This work is supported by the National Heart, Lung, and Blood Institute (grants HL-02205, HL-41009, HL-35718, and HL-32459), Lilly Research Laboratories, and by Merck-Frosst Center for Therapeutic Research.

\section{References}

1. Ray, D. W., C. Hernandez, N. Munoz, A. R. Leff, and J. Solway. 1988. Bronchoconstriction elicited by dry gas hyperpnea in guinea pigs. J. Appl. Physiol. 65(2):934-939.

2. Ray, D. W., S. Eappon, C. Hernandez, M. Jackson, A. R. Leff, and J. Solway. 1990. Distribution of airway narrowing during hyperpnea-induced bronchoconstriction in guinea pigs. J. Appl. Physiol. 69(4):1323-1329.

3. Solway, J., and A. R. Leff. 1991. Sensory neuropeptides and airway function. J. Appl. Physiol. 71(6):2077-2087.

4. Ray, D. W., C. Hernandez, A. R. Leff, and J. Solway. 1989. Tachykinins mediate bronchoconstriction elicited by isocapnic hyperpnea in guinea pigs. $J$. Appl. Physiol. 66(3):1108-1112.

5. Garland, A., D. W. Ray, C. M. Doerschuk, M. Jackson, S. Eappen, L. Alger, and J. Solway. 1991. The role of tachykinins in hyperpnea-induced bronchovascular hyperpermeability in guinea pigs. J. Appl. Physiol. 70(1):27-35.

6. Myers, A., and B. J. Undem. 1992. Tachykinin-mediated stimulation of bronchial parasympathetic ganglion neurons. Am. Rev. Respir. Dis. 145(4, Pt. 2):A261. (Abstr.)

7. Snider, R. M., J. W. Constantine, J. A. Lowe III, K. P. Longo, W. S. Lebel, H. A. Woody, S. E. Drozda, J. C. Desai, F. J. Vinick, R. W. Spencer, and H. J. Hess. 1991. A potent nonpeptide antagonist of the substance $P(N K-1)$ receptor. Science (Wash. DC). 251:435-437.

8. Emonds-Alt, X., P. Vilain, P. Goulaouic, V. Proietto, D. Van Broeck, C. Advenier, E. Naline, G. Neliat, G. Le Fur, and J. C. Breliere. 1992. A potent and selective non-peptide antagonist of the neurokinin $A\left(\mathrm{NK}_{2}\right)$ receptor. Life Sci. 50:101-106.

9. Watling, K. J. 1992. Nonpeptide antagonists herald new era in tachykinin research. Trends Pharmacol. Sci. 13:266-269.

10. Lei, Y.-H., P. J. Barnes, and D. F. Rogers. 1992. Inhibition of neurogenic plasma exudation in guinea-pig airways by CP-96,345, a new non-peptide $\mathrm{NK}_{1}$ receptor antagonist. Br. J. Pharmacol. 105:261-262.

11. Delay-Goyet, P., and J. M. Lundberg. 1991. Cigarette smoke-induced airway oedema is blocked by the $\mathrm{NK}_{1}$ antagonist, CP-96,345. Eur. J. Pharmacol. 203:157-158.

12. Ray, D. W., C. Hernandez, S. Eappen, and J. Solway. 1991. Time course of bronchoconstriction induced by dry gas hyperpnea in guinea pigs. J. Appl. Physiol. 70(2):504-510. 
13. Shore, S. A., and J. M. Drazen. 1989. Enhanced airway responses to substance $\mathrm{P}$ after repeated challenge in guinea pigs. J. Appl. Physiol. 67:955-961.

14. Holzer, P. 1991. Capsaicin: cellular targets, mechanisms of action, and selectivity for thin sensory neurons. Pharmacol. Rev. 43(2):143-201.

15. Lundberg, J. M., C. R. Martling, A. Saria, K. Folkers, and S. Rosell. 1983. Cigarette smoke-induced airway oedema due to activation of capsaicin-sensitive vagal afferents and substance $P$ release. Neuroscience. 10:1361-1368.

16. Umeno, E., D. M. McDonald, and J. A. Nadel. 1990. Hypertonic saline increases vascular permeability in the rat trachea by producing neurogenic inflammation. J. Clin. Invest. 85(6):1905-1908.

17. Sestini, P., M. Dolovich, C. Vancheri, R. H. Stead, J. S. Marshall, M. Perdue, J. Gauldie, and J. Bienenstock. 1989. Antigen-induced lung solute clearance in rats is dependent on capsaicin-sensitive nerves. Am. Rev. Respir. Dis. 139:401-406.

18. Kanemura, T., J. Tamaoki, N. Sakai, K. Kobayashi, and T. Takizawa. 1989. The effect of $N$-formyl-methionyl-leucyl-phenyl-alanine on cholinergic neurotransmission and its modulation by enkephalinase in rabbit airway smooth muscle. Regul. Pept. 26:107-116.

19. Martins, M. A., S. A. Shore, and J. M. Drazen. 1991. Release of tachykinins by histamine, methacholine, PAF, $\mathrm{LTD}_{4}$, and substance $\mathrm{P}$ from guinea pig lungs. Am. J. Physiol. (Lung Cell Molec. Physiol. 5) 261:L449-L455.
20. Regoli, D., G. Drapeau, S. Dion, and P. D’Orleans-Juste. 1987. Pharmacological receptors for substance P and neurokinins. Life Sci. 40:109-117.

21. Helke, C. J., J. E. Krause, P. W. Mantyh, R. Couture, and M. J. Bannon. 1990. Diversity in mammalian tachykinin peptidergic neurons: multiple peptides, receptors, and regulatory mechanisms. FASEB (Fed. Am. Soc. Exp. Biol.) J. 4:1606-1615.

22. Schmidt, A. W., S. McLean, and J. Heym. 1992. The substance $P$ receptor antagonist CP-96,345 interacts with $\mathrm{Ca}^{2+}$ channels. Eur. J. Pharmacol. 215:351352.

23. Bleakman, D., J. R. Brorson, and R. J. Miller. 1990. The effect of capsaicin on voltage-gated calcium currents and calcium signals in cultured dorsal root ganglion cells. Br. J. Pharmacol. 101:423-431.

24. Garland, A., D. Ray, T. R. Hsiue, L. Alger, M. B. Hershenson, and J. Solway. 1991. Role of eicosanoids in hyperpnea-induced bronchoconstriction (HIB) and bronchovascular hyperpermeability (HIBVH) in guinea pigs. Am. Rev. Respir. Dis. 143(4):A539. (Abstr.)

25. Kelly, L., J. Kolbe, W. Mitzner, E. W. Spannhake, B. Bromberger-Barnea, and $\mathrm{H}$. Menkes. 1986. Bronchial blood flow affects recovery from constriction in dog lung periphery. J. Appl. Physiol. 60:1954-1959.

26. Persson, C. G. A. 1987. Leakage of macromolecules from the tracheobronchial microcirculation. Am. Rev. Respir. Dis. 135(6, Pt. 2):S71-S75. 